九州大学学術情報リポジトリ

Kyushu University Institutional Repository

\title{
Synthesis of Ti0_2-Si0_2-Cu0 Nanocomposite Material and Its Activities for Self-cleaning
}

Ibrahim Harya Dwirekso

Department of Chemical Engineering, Faculty of Engineering, Universitas Indonesia

Ibadur rohman, Muhammad

Department of Chemical Engineering, Faculty of Engineering, Universitas Indonesia

Slamet

Department of Chemical Engineering, Faculty of Engineering, Universitas Indonesia

https://doi.org/10.5109/4055234

出版情報 : Evergreen. 7 (2)，pp.285-291，2020-06. 九州大学グリーンテクノロジー研究教育センター バージョン：

権利関係 : 


\title{
Synthesis of $\mathrm{TiO}_{2}-\mathrm{SiO}_{2}-\mathrm{CuO}$ Nanocomposite Material and Its Activities for Self-cleaning
}

\author{
Ibrahim Harya Dwirekso ${ }^{1}$, Muhammad Ibadurrohman ${ }^{1}$, Slamet ${ }^{1, *}$ \\ ${ }^{1}$ Department of Chemical Engineering, Faculty of Engineering, Universitas Indonesia, Depok, Indonesia \\ *Corresponding author: E-mail: slamet@che.ui.ac.id; slamet.dtk.ui@gmail.com
}

(Received November 7, 2019; Revised May 2, 2020; accepted May 21, 2020).

\begin{abstract}
Synthesis of $\mathrm{TiO}_{2}-\mathrm{SiO}_{2}-\mathrm{CuO}$ nanocomposite material have been prepared by Photo Assisted Deposition (PAD) and Stober method to obtain self-cleaning material which is useful for life commodity. The self-cleaning ability were measured by its hydrophilicity, furthermore, the nanocomposite also have been evaluated for its performance in the decolorization of methylene blue. The order of PAD and Stober method in nanocomposite synthesis were adjusted for different nanocomposite morphology. The characteristic of $\mathrm{TiO}_{2}-\mathrm{SiO}_{2}-\mathrm{CuO}$ nanocomposite consist the chemical bonding of Ti-O-Si which could enhance its hydrophilicity for self-cleaning purposes and the $\mathrm{CuO}$ dopant in the nanocomposite enhance the light responses to visible region. $\mathrm{The}^{\mathrm{SiO}_{2}}$ addition affect the morphological structure, then enhance the nanocomposite surface area, adsorption of methylene blue, and its hydrophilicity. So the $\mathrm{TiO}_{2}-\mathrm{SiO}_{2}-\mathrm{CuO}$ nanocomposite exhibit much higher performance in decolorization of methylene blue which could reach $80 \%$ for 5 minutes and has $6^{0}$ contact angle compared with $\mathrm{CuO}-\mathrm{TiO}_{2}$. The morphology 1 nanocomposite which most of the $\mathrm{CuO}$ were at $\mathrm{TiO}_{2}$ lattice possess superior self-cleaning ability than the morphology 2 nanocomposite which most of the $\mathrm{CuO}$ inhibits $\mathrm{SiO}_{2}$.
\end{abstract}

Keywords: Hydrophilicity; Nanocomposite; Photodegradation; PAD; Self-cleaning

\section{Introduction}

There are many problems of fabric clothes that are a disturbance for daily life, one of them is that the clothes must be cleaned everytime it was used especially when it was made of pure cotton that is often exposed to dirt, so research lately about the development of self-cleaning fabric is an objective sought by the textile industry in the framework of new products classified as intelligents fabrics ${ }^{1), 2)}$. The cost saving using these fabrics, presenting a total or a partial self-cleaning properties, is one benefit. Such an innovation comprises $\mathrm{TiO}_{2}$ deposited in the fabric surface, $\mathrm{TiO}_{2}$ was shown in the last decade to be the best candidate for a photocatalytic applications ${ }^{2-13}$ ). So in this paper, the material that will be reviewed about its selfcleaning activity is $\mathrm{TiO}_{2}$ which is measured by its hydrophilicity and decolorization of organic compound such as methylene blue. Nano-sized $\mathrm{TiO}_{2}$ exhibits selfcleaning activity under light irradiation due to the oxygen vacancies and ROS (Reactive Oxygen Species) formation because of the excitated electron and hole ${ }^{5}$. Generally, $\mathrm{TiO}_{2}$ absorbs UV light with wavelength shorter than 380 $\mathrm{nm}$, with the band gap energy of different forms of $\mathrm{TiO}_{2}$ is $3.2 \mathrm{eV}$ for anatase, $3.0 \mathrm{eV}$ for rutile, and only make use of $3-4 \%$ of the solar energy ${ }^{14), 15}$. The high recombination rate of photogenerated electron-hole pair and lack of utilization of sunlight that reduced the ROS formation has to be improved and many reports focus on effective way to utilize the $\mathrm{TiO}_{2}$ nanoparticle on visible light region. For instances, doping is one of the most effective way to reduce the electron-hole pair recombination, energy gap and thus shift the absorption spectrum to the visible region. Also in the recent years, doping with transition metal can increase the ROS formation from $\mathrm{TiO}_{2}$ such as $\mathrm{Ag}^{16), 17)}$, $\mathrm{Fe}^{3+18)}, \mathrm{Pt}^{19), 20)}$ and $\mathrm{Cu}^{21)}$, for owning a cheaper cost, $\mathrm{Cu}$ doped in the form of $\mathrm{CuO}$ is more likely to be used.

In the recent studies, enhancing the hydrophilicity of $\mathrm{TiO}_{2}$ is also an objective to increase its self-cleaning ability, that was done by compositing $\mathrm{TiO}_{2}$ with other material that could contain water such as silica in the form of silica dioxide $\left(\mathrm{SiO}_{2}\right)^{11), 22), 23)}$. $\mathrm{SiO}_{2}$ is an optical transparancy material that can help the heat stabilization of $\mathrm{TiO}_{2}$ anatase and also can enhanced the the hydrophilicity on the surface by increasing its acidity, beside that, the chemical bond between $\mathrm{TiO}_{2}$ and $\mathrm{SiO}_{2}$ could maintain the hydrophilicity much longer even in the absence of light irradiation ${ }^{4}$. The combination of $\mathrm{Cu}-$ doped $\mathrm{TiO}_{2}$ and $\mathrm{SiO}_{2}$ nanocomposite also have been studied to improve the ROS formation even in visible light because of its synergistic effect ${ }^{8)}$, but the hydrophilicity of the nanocomposite remains unexplored. However, the development from the nanocomposite perspective are still rarely been explored such as the effect of nanocomposite morphology to the self-cleaning activities. As far as its 
known, different synthesis of the nanocomposite procedure could cause different morphology and with the same composition, the nanocomposite would have a different properties ${ }^{24)}$. Also, the metal doped in the $\mathrm{TiO}_{2}$ lattice and metal in the surface of $\mathrm{SiO}_{2}$ which act as an dispersal agent could have different antibacterial activities ${ }^{25)}$, which could be further explored the effect of the position of $\mathrm{CuO}$ in the nanocomposite to its selfcleaning activities.

Therfore, the key objective of this study is to investigate the enhanced self-cleaning mechanism of different $\mathrm{TiO}_{2}$ $\mathrm{SiO}_{2}-\mathrm{CuO}$ nanocomposite. Synthesis of $\mathrm{TiO}_{2}-\mathrm{SiO}_{2}-\mathrm{CuO}$ nanocomposite were prepared by Photo Assisted Deposition (PAD) to added the $\mathrm{CuO}$ dopant in the nanocomposite and Stober method to added the $\mathrm{SiO}_{2}$ in the nanocomposite. The order of PAD and Stober method in nanocomposite synthesis were adjusted for different nanocomposite morphology.

\section{Experimentals}

\subsection{Materials}

The material used in this study were Aquadest, Ethanol MERCK, Methanol MERCK, Ammonia water 25\% MERCK, Nitric Acid $\left(\mathrm{HNO}_{3}\right)$ MERCK, Tetraethyl Orthosilicate (TEOS) MERCK, $\mathrm{TiO}_{2}$ Evonik P25, Copper Chloride $\left(\mathrm{CuCl}_{2} .2 \mathrm{H}_{2} \mathrm{O}\right)$ and Methylene Blue. While the tool used is a photocatalyst reactor, sonicator, UV lamp $15 \mathrm{~W}$, beaker, $\mathrm{pH}$ meter, pipette, volumetric pipette, magnetic stirrer, magnetic bar, stopwatch, Photoreactor, and UV-Vis Spectrophotometry.

\subsection{Methods}

The first step is to prepared the $\mathrm{CuO}-\mathrm{TiO}_{2}$ catalyst which were prepared by PAD method. 2 g of $\mathrm{TiO}_{2} \mathrm{P} 25$ were dissolved on $170 \mathrm{ml}$ aquadest then add a dropplet of $\mathrm{HNO}_{3}$ to be sonicated for 30 minutes and $100 \mathrm{ml} \mathrm{CuCl}$ solution with $3 \%$ weight $\mathrm{Cu}$ to $\mathrm{TiO}_{2}$ were made. $\mathrm{TiO}_{2}$ soles and $\mathrm{CuCl}_{2}$ solution were mixed to be irradiated with UV light for 6 hours with the addition of $30 \mathrm{ml}$ methanol. After that the solution were washed several times then dried in hot plate and grounded to obtain $\mathrm{Cu}$ doped $\mathrm{TiO}_{2}$ catalyst. After that $\mathrm{TiO}_{2}-\mathrm{SiO}_{2}-\mathrm{CuO}$ were prepared by stober method. Solution contain of $24 \mathrm{ml}$ of ammonia water and $20 \mathrm{ml}$ of anhydrous ethanol were prepared, various amount of Tetraethyl orthosilicate (TEOS) and $2 \mathrm{ml}$ of aquadest were put into the solution. 1 gr of $\mathrm{Cu}$ doped $\mathrm{TiO}_{2}$ that has been washed and $8 \mathrm{ml}$ of aquadest were put afterwards into the solution. The solution were stirred in ambient air for 3 hours then dried in hotplate and ground to be calcinated at $300^{\circ} \mathrm{C}$ in atmospheric furnace mantain 2 hours to obtain $\mathrm{Cu}$ doped $\mathrm{TiO}_{2}-\mathrm{SiO}_{2}$ nanocomposite. The order of PAD and Stober method in synthesis were adjusted for different nanocomposite morphology. The morphology illustration can be seen in Figure 1a. The difference of both morphology in Figure 1a that based on the synthesis method are the distribution of the $\mathrm{CuO}$ in the nanocomposite, where in morphology 1 (M1) nanocomposite, $\mathrm{CuO}$ mostly inhibits the $\mathrm{TiO}_{2}$ lattice while for the morphology 2 (M2), $\mathrm{CuO}$ were mostly inhibits the pore of $\mathrm{SiO}_{2}$ or/and the surface of $\mathrm{TiO}_{2}$.

The nanocomposite will be characterized with Fourier Transformed Infrared Spectroscopy (FTIR), UV-Vis Diffuse Reflectance Spectroscopy (DRS), Surface Area Analyzer and Field Emission Scanning Electron Microscopy (FE-SEM)/Energy Dispersive X-ray (EDX) then to be evaluated for its self-cleaning activities. The decolorization of methylene blue (MB) were done in a photoreactor which consist 4 UV lamps, 7 ppm of $300 \mathrm{ml}$ methylene blue were put into a beaker and $0.3 \mathrm{~g}$ of $\mathrm{TiO}_{2}-$ $\mathrm{SiO}_{2}-\mathrm{CuO}$ nanocomposite were also put in that beaker, the beaker were stirred in a magnetic stirrer for 2 hours, the methylene blue sample were taken to be measured in UVVis Spectrophotometry. The hydrophilicity of the nanocomposite were measured by the contact angle of water in a thin film after irradiated by a single UV lamp for 30 minutes with a Contact Angle Meter (CAM), the nanocomposite were diluted in a aquadest solution then coated to a thin glass to be sonicated and finally cured in an oven. The self-cleaning mechanism methods of the nanocomposite could be described in Figure 1b, the oxygen vacancies occured by photocatalyst process (excitation of electron leaving a hole), which the hole oxidized the $\mathrm{O}_{2}$ atom to leave its structure, that cause the $\mathrm{TiO}_{2}$ possess hydrophilic properties which formed a thin layer of $\mathrm{H}_{2} \mathrm{O}$ adsorbed. Thin layer prevent dirt from contacting directly to the surface of a film which could be easily washed off, and if is an organic compound, by photodegradation process, would be reduced to $\mathrm{CO}_{2}$ and $\mathrm{H}_{2} \mathrm{O}$. The more hydrophilic properties of the nanocomposite, the better it could prevent dirt ${ }^{1), 4)}$.

(a)

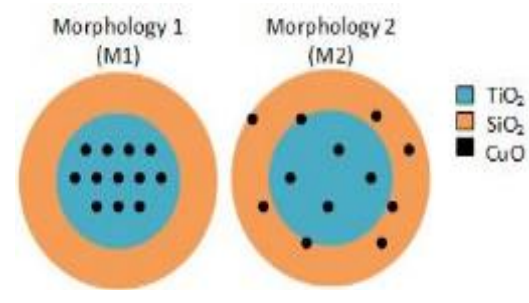

(b)
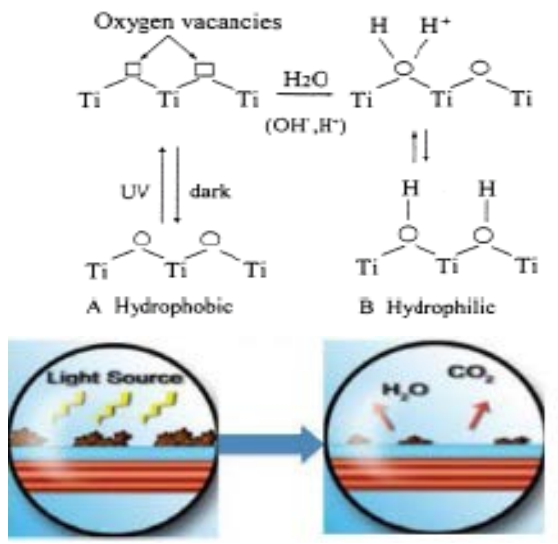

Fig. 1: Illustration of (a) Nanocomposite Morphology and (b) Self-Cleaning Mechanism 


\section{Results and discussion}

\subsection{Characteristic of The Nanocomposite}

The FTIR spectrum of several $\mathrm{TiO}_{2}-\mathrm{SiO}_{2}-\mathrm{CuO}$ nanocomposite $\left(\% \mathrm{SiO}_{2}\right.$ based on mole) is shown in Figure 2. It contain bands at $3400-3600 \mathrm{~cm}^{-1}, 1630 \mathrm{~cm}^{-1}, 1060$ $1220 \mathrm{~cm}^{-1}, 941 \mathrm{~cm}^{-1}$, and 590-647 $\mathrm{cm}^{-1}$. Basically, all the $\mathrm{TiO}_{2}-\mathrm{SiO}_{2}-\mathrm{CuO}$ has the same wavenumber spectrum but the intensity were different according to the mole percentage of the $\mathrm{SiO}_{2}$ in the nanocomposite and its clearly that the $\mathrm{Cu}$-doped $\mathrm{TiO}_{2}$ doesn't contain functional group of $\mathrm{SiO}_{2}$ spectrum in the FTIR analysis. The bands at $3400-3600 \mathrm{~cm}^{-1}$ and $1630 \mathrm{~cm}^{-1}$ are assigned to $\mathrm{OH}$ bending and strecthing vibrations respectively. It can be defined as a $\mathrm{Ti}-\mathrm{OH}, \mathrm{Si}-\mathrm{OH}$, and $\mathrm{O}-\mathrm{H}$ bending related to physically absorbed moisture (interaction of hydrogen bonds with water molecule) ${ }^{26)}$, the bands at 1060-1220 $\mathrm{cm}^{-1}$ is the characteristic bonds of $\mathrm{Si}-\mathrm{O}-\mathrm{Si}$ asymmetric stretching and at $941 \mathrm{~cm}^{-1}$ refers to Ti-O-Si asymmetric stretching, thus the Ti-O-Si bond were developed when the calcination process occured, The effect of Ti-O-Si bond can increase the surface hydrophilicity of the nanocomposite, so it could adsorbed more $\mathrm{H}_{2} \mathrm{O}$ at the surface of the nanocomposite. The peak at 590-647 $\mathrm{cm}^{-1}$ were the characteristic of Ti-O-Ti bonding which attributed to $\mathrm{TiO}_{2}$. New absorption peak were detected at wavenumber $2335 \mathrm{~cm}^{-1}$, it may be attributed to lattice defect cause by heat treatment ${ }^{2}$, so it was predicted that dopants of $\mathrm{Cu}$ has been incorporated into the $\mathrm{TiO}_{2}$ to substitute $\mathrm{Ti}^{4+}$. Beside that, it can be seen in both morphology, there were no specific peaks of $\mathrm{Si}-\mathrm{O}-\mathrm{Cu}$ which indicated that $\mathrm{Cu}$ were uniformly dispersed in the $\mathrm{TiO}_{2}$ lattice or $\mathrm{SiO}_{2}$ as $\mathrm{CuO}$, the form of $\mathrm{Cu}$ as $\mathrm{CuO}$ can be predicted from the synthesis method ${ }^{7-10}$ ).

The DRS response in Figure 3 showed that the $\mathrm{Cu}$ doped in $\mathrm{TiO}_{2}$ lattice could enhance the visible light respons of the photocatalyst showed by the increase of absorbance in wavelength between 400-800 nm and lowered its bandgap, the bandgap were calculated by Kulbelka-Munk equation ${ }^{9)}$. The addition of $\mathrm{SiO}_{2}$ to $\mathrm{CuO}-$ $\mathrm{TiO}_{2}$ catalyst slightly affect the visible light response and bandgap of the photocatalyst that can be seen in Table 1, $\mathrm{SiO}_{2}$ is known to have optical properties so it doesn't block the light at the surface of $\mathrm{TiO}_{2}$ when $\mathrm{SiO}_{2}$ act as a shell in the nanocomposite. There were no significant difference between the bandgap of $\mathrm{CuO}-\mathrm{TiO}_{2}-33 \% \mathrm{SiO}_{2}$ M1 and M2 nanocomposite, even if the CuO doesn't inhibits the $\mathrm{TiO}_{2}$ lattice which doesn't play the role as electron trapper, it could still lower the bandgap because the effect of surface plasmon resonance ${ }^{7 \text { ). }}$.

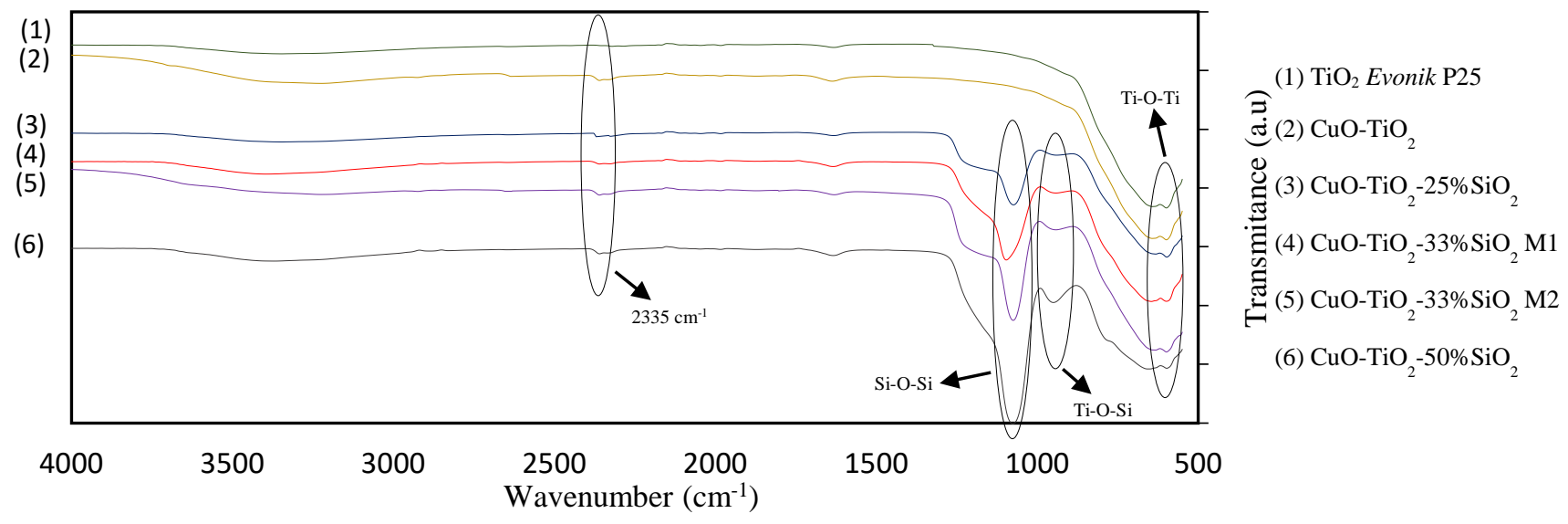

Fig 2. FTIR Spectrums of the Nanocomposite

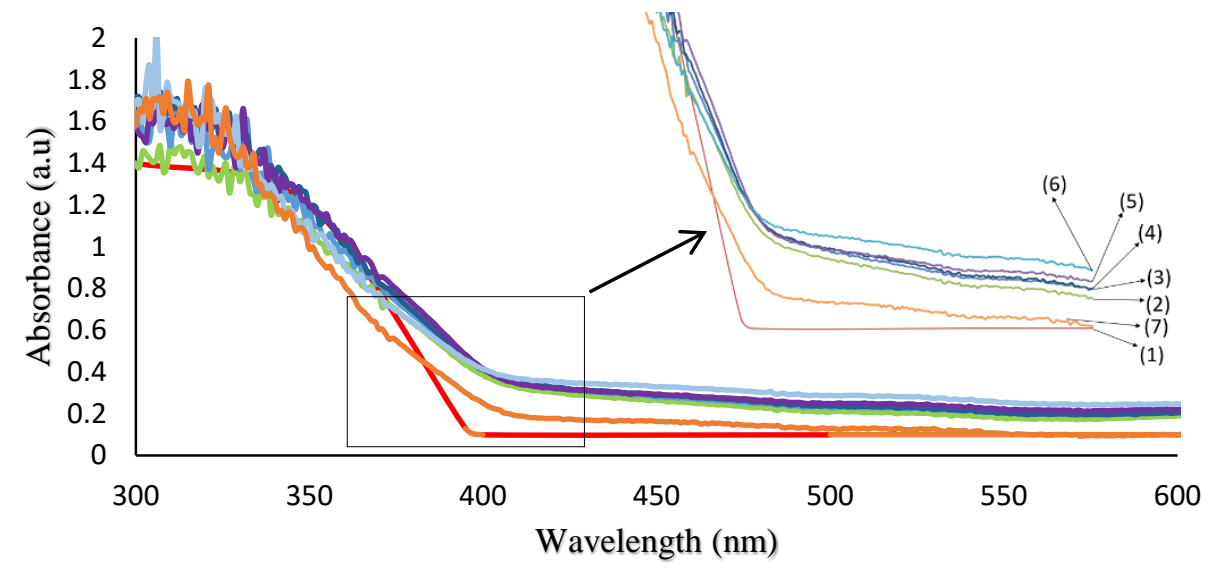

Fig 3. DRS patterns of the Nanocomposite
(1) $\mathrm{TiO}_{2}$ Evonik P25

(2) $\mathrm{CuO}-\mathrm{TiO}_{2}$

(3) $\mathrm{CuO}-\mathrm{TiO}_{2}-16 \% \mathrm{SiO}_{2}$

(4) $\mathrm{CuO}-\mathrm{TiO}_{2}-25 \% \mathrm{SiO}_{2}$

(5) $\mathrm{CuO}-\mathrm{TiO}_{2}-33 \% \mathrm{SiO}_{2} \mathrm{M} 1$

(6) $\mathrm{CuO}-\mathrm{TiO}_{2}-50 \% \mathrm{SiO}_{2}$

(7) $\mathrm{CuO}-\mathrm{TiO}_{2}-33 \% \mathrm{SiO}_{2} \mathrm{M} 2$ 
FE-SEM analysis of the nanocomposite indicated that addition of $\mathrm{SiO}_{2}$ on $\mathrm{Cu}$ doped $\mathrm{TiO}_{2}$ can affect the surface morphology of the catalyst, however there was no significant effect on the aggregate sizes. The granular shape on the $\mathrm{TiO}_{2}-\mathrm{SiO}_{2}-\mathrm{CuO}$ nanocomposite is the silica that shaped as a shell in the $\mathrm{TiO}_{2}$ surface. As the silica content increased, the agglomeration of silica particle also increased as can be seen in the FE-SEM images based on Figure 4. The elemental weight of $\mathrm{Cu}, \mathrm{Ti}$, Si can be seen in Table 1 which is measured by EDX analysis. The $\mathrm{Cu}$ and $\mathrm{Ti}$ content decrease by the increase of the silica content in the nanocomposite.

Table 1. Composition and Bandgap of Several Nanocomposite

\begin{tabular}{|c|c|c|c|c|c|c|}
\hline \multirow{2}{*}{ Sample } & \multicolumn{4}{|c|}{ \% weight } & \multirow{2}{*}{ Bandgap (eV) } & \multirow{2}{*}{$\begin{array}{c}\text { Surface } \\
\text { Area }\left(\mathrm{m}^{2} / \mathrm{g}\right)\end{array}$} \\
\hline & $\mathbf{C u}$ & $\mathbf{O}$ & $\mathbf{T i}$ & Si & & \\
\hline $\mathrm{CuO}-\mathrm{TiO}_{2}$ & 3.41 & 35.98 & 60.61 & 0 & 2.92 & 73.99 \\
\hline $\mathrm{CuO}-\mathrm{TiO}_{2}-16 \% \mathrm{SiO}_{2}$ & 3.23 & 14.83 & 79.02 & 2.92 & 2.93 & - \\
\hline $\mathrm{CuO}-\mathrm{TiO}_{2}-33 \% \mathrm{SiO}_{2} \mathrm{M} 1$ & 1.66 & 44.79 & 43.24 & 10.31 & 2.99 & 128.15 \\
\hline $\mathrm{CuO}-\mathrm{TiO}_{2}-33 \% \mathrm{SiO}_{2} \mathrm{M} 2$ & 1.92 & 42.65 & 43.73 & 11.70 & 3.02 & 99.13 \\
\hline
\end{tabular}

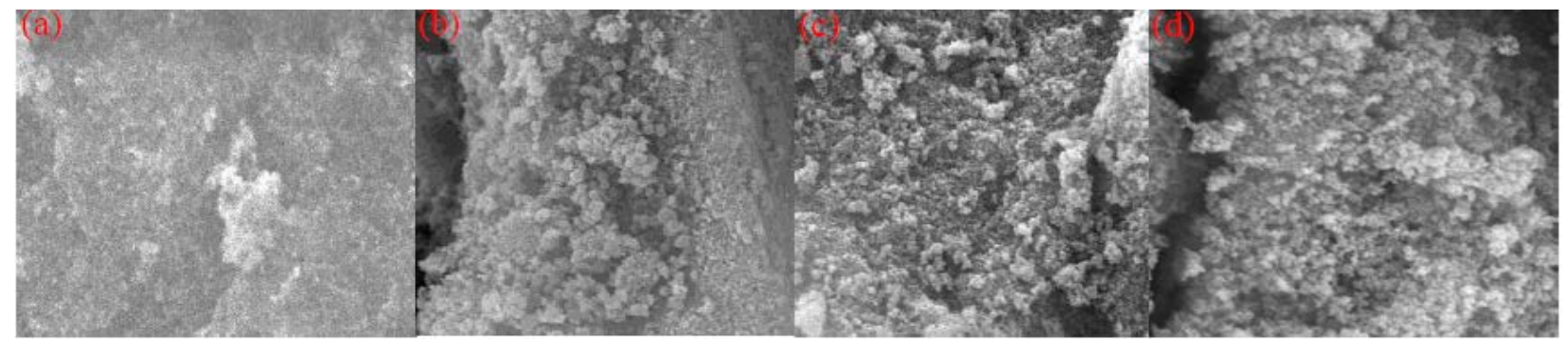

Fig 4 Nanocomposite Morphology at 20000x magnitude (a) $\mathrm{CuO}-\mathrm{TiO}_{2}$, (b) $\mathrm{CuO}-\mathrm{TiO}_{2}-16 \% \mathrm{SiO}_{2}$,

(c) $\mathrm{CuO}-\mathrm{TiO}_{2}-33 \% \mathrm{SiO}_{2} \mathrm{M} 1$, and (d) $\mathrm{CuO}-\mathrm{TiO}_{2}-33 \% \mathrm{SiO}_{2} \mathrm{M} 2$

\subsection{Decolorization of Methylene Blue}

Decolorization of MB consisted 2 process, which were adsorption and photodegradation of $\mathrm{MB}$, the adsorption depends on the surface area or hydrophilicity of the nanocomposite to adsorbed more MB in the solution and the photodegradation depends on the $\mathrm{OH}$ radicals formation to photo oxidized the $\mathrm{MB}$ to $\mathrm{CO}_{2}$ and $\mathrm{H}_{2} \mathrm{O}$. Figure 5 (a) showed that the addition of $\mathrm{SiO}_{2}$ will increase the efficiency of $\mathrm{MB}$ decolorization until $80 \%$ in 5 minutes, the effect of $\mathrm{SiO}_{2}$ in the nanocomposite was increasing the surface hydrophilicity of the photocatalyst (by Ti-O-Si bond), so it can adsorb more $\mathrm{H}_{2} \mathrm{O}$ and with the charge separation rate is higher because of the $\mathrm{CuO}$ dopant, the hole can easily meet another $\mathrm{OH}^{-}$from the adsorbed $\mathrm{H}_{2} \mathrm{O}$ in the surface so it could produce more $\mathrm{OH}$ radicals. On the contrary when the $\mathrm{SiO}_{2}$ content increase, $\mathrm{TiO}_{2}$ content is decrease, so the photogenerated holes also decrease and when it comes to the point that the decrease of holes becomes more dominant than the holes oxidized the hydroxyl group, the total $\mathrm{OH}$ radicals produced will be lower to degradate the $\mathrm{MB}$ and would reduce its decolorization efficiency. So the synergis effect of $\mathrm{SiO}_{2}$ addition with the $\mathrm{TiO}_{2}$ to produce more $\mathrm{OH}$ radicals would occured until $33 \% \mathrm{SiO}_{2}$ mole composition which higher than 33\% could reduce the MB decolorization efficiency.

(a)

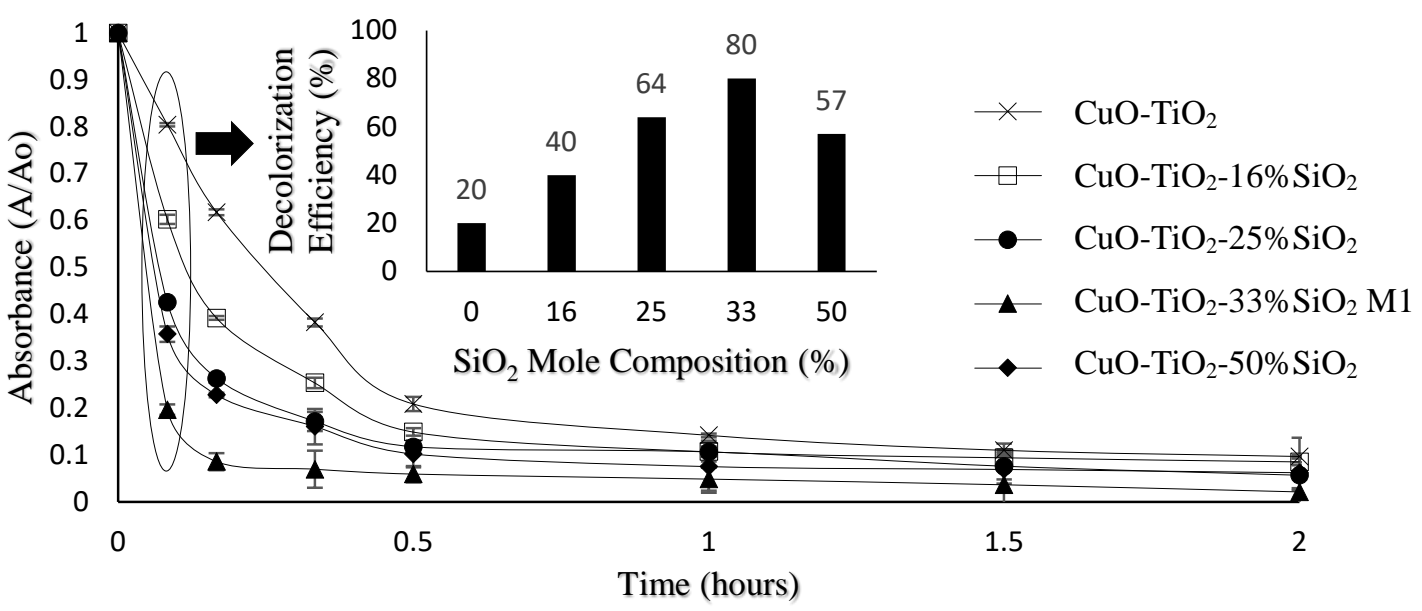


(b)

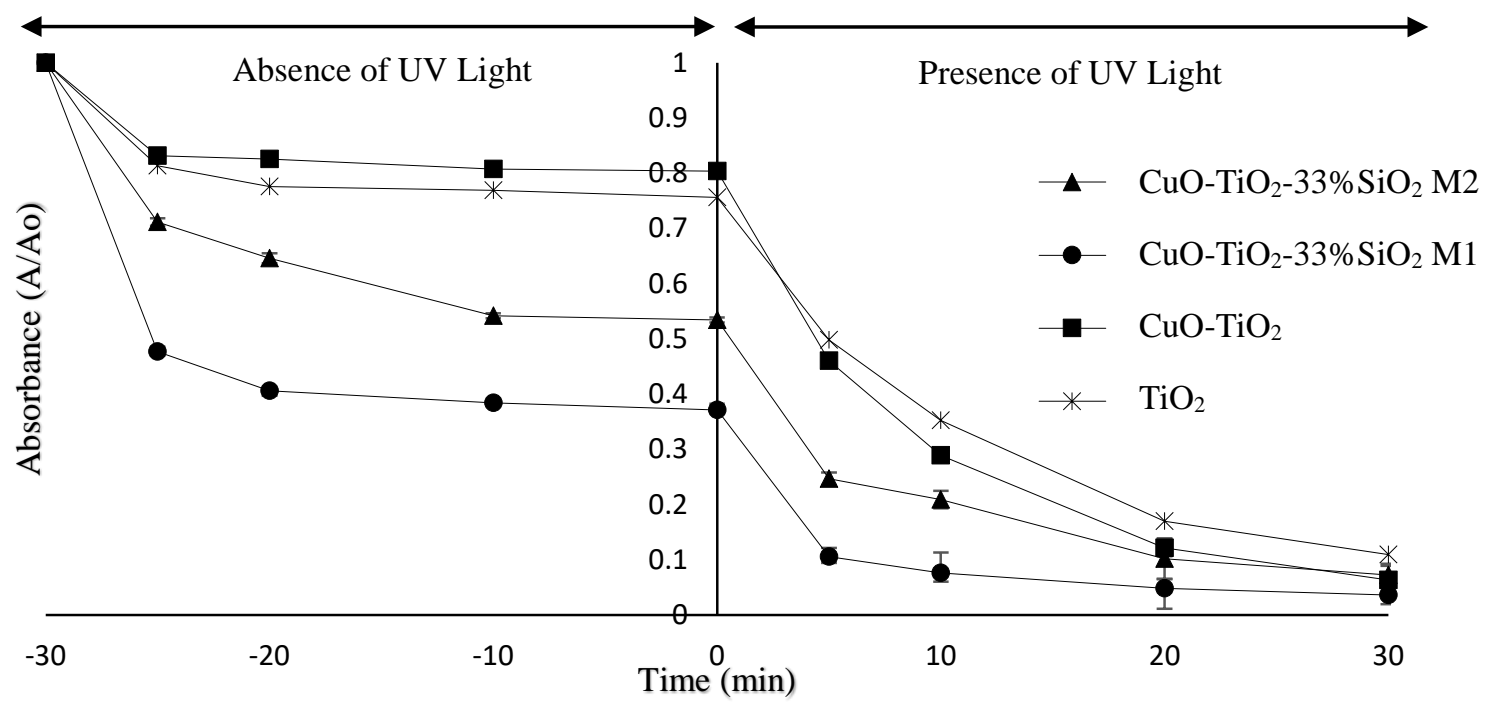

Fig 5. MB Decolorization (a) $\mathrm{TiO}_{2}-\mathrm{SiO}_{2}-\mathrm{CuO}$ Nanocomposite (b) in the absence and presence of UV light

Based on Figure 5 (b) the decolorization process were caused by the adsorption of the catalyst/nanocomposite surface which depends on its surface area in the absence of photon energy. There was a time span where there was no significant decrease in absorbance, this was believed because methylene blue has covered the entire surface of the catalyst/nanocomposite and because of the absence of photon energy there was no photodegradation process occured. The addition of $\mathrm{SiO}_{2}$ to nanocomposite could increase the methylene blue adsorption ability because it increases the nanocomposite surface area especially if $\mathrm{SiO}_{2}$ was amorphous, there are significant differences between M1 and M2 nanocomposites in adsorbing methylene blue where M1 nanocomposite is superior. This occured because the surface area of M1 nanocomposite is larger than M2 nanocomposite based on Table 1, a decrease in surface area was happened because referring to the morphological illustrations in M2 nanocomposite, $\mathrm{CuO}$ mostly inhibits at amorphous $\mathrm{SiO}_{2}$ which would likely covered its pore. When the UV lamp was turned on, the photodegradation process of methylene blue begins to occur, so that the methylene blue absorbance will begin to decrease. Catalysts/nanocomposites has different photodegradation performance and because of the different adsorption effects causes the initial absorbance in the beginning of photodegradation were dissimilar, so to compare the photodegradation ability, it used the kinetics reaction rate approach with 2nd orde reaction. The value of the reaction rate constant for $\mathrm{TiO}_{2}$ catalyst in photodegradation of methylene blue is $0.2571 \mathrm{~L} / \mathrm{mg}$.min and the catalyst $3 \% \mathrm{CuO}-\mathrm{TiO}_{2}$ has a greater reaction rate constant of $0.4282 \mathrm{~L} / \mathrm{mg}$.min. $\mathrm{CuO}-\mathrm{TiO}_{2}-33 \% \mathrm{SiO}_{2} \mathrm{M} 1$ nanocomposite has a reaction rate constant of 0.8968 $\mathrm{L} / \mathrm{mg}$.min, this can be achieved because of the synergistic effect between the dopant of $\mathrm{CuO}$ and $\mathrm{SiO}_{2}$ composites in increasing $\mathrm{OH}$ radical production. But $\mathrm{M} 2$ nanocomposite has a reaction rate constant lower than half of $\mathrm{CuO}-\mathrm{TiO}_{2}-$ $33 \% \mathrm{SiO}_{2} \mathrm{M} 1$ nanocomposite which is equal to 0.4004
L/mg.min. This shows that the dopant of $\mathrm{CuO}$ plays a major role in producing $\mathrm{OH}$ radicals as an electron trapper and in accordance with $\mathrm{M} 2$ morphological, most $\mathrm{CuO}$ dispersed in $\mathrm{SiO}_{2}$ so that the role of $\mathrm{CuO}$ as an electron trapper is very small resulting in much lower hole and electron separations even from $3 \% \mathrm{CuO}-\mathrm{TiO}_{2}$ catalysts, hence the hydroxyl ions that were at the surface of the nanocomposite only a few meet holes which results in a lower $\mathrm{OH}$ radical/ROS production that lower its photodegradation of methylene blue ability.

\subsection{Hydrophilicity in a Thin Film}

Figure 6a showed that all nanocomposites have a contact angle below $30^{\circ}$ (blank thin film has a contact angle of $45^{\circ}$ ) that meets the hydrophilic standard even the $\mathrm{CuO}-\mathrm{TiO}_{2}-33 \% \mathrm{SiO}_{2} \mathrm{M} 1$ nanocomposite has a contact angle near $5^{0}$ which indicates a superhydrophilic properties ${ }^{23)}$. The hydrophilic properties of $\mathrm{TiO}_{2}-\mathrm{SiO}_{2}$ $\mathrm{CuO}$ nanocomposites are due to the presence of oxygen vacancies and physisorption or chemisorption of $\mathrm{H}_{2} \mathrm{O}$ produced in the photocatalyst process. The addition of $\mathrm{SiO}_{2}$ to the nanocomposite can increase the hydrophilicity because the presence of $\mathrm{Ti}-\mathrm{O}-\mathrm{Si}$ bonds that causes the surface acidity to increase so that more water could be adsorbed at the surface of the nanocomposite which cause the increase of physisorption and chemisorption of hydroxyl group to produce more thin layers ${ }^{4}$.

(a)

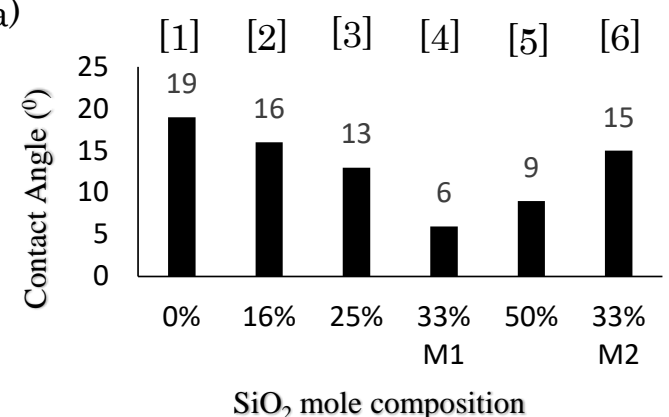

$\mathrm{SiO}_{2}$ mole composition 
(b)
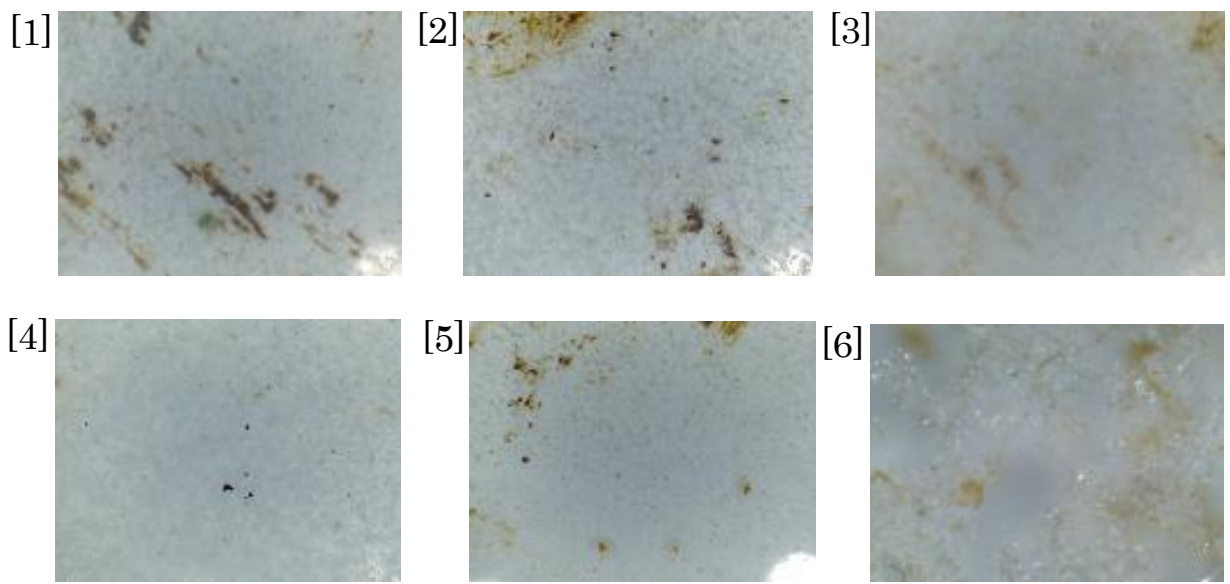

Fig 6. (a) Contact Angle of Water Droplets and (b) Viable Dirt at the Surfaces (20x magnitude) of Thin Glass Coated with Each $\mathrm{TiO}_{2}-\mathrm{SiO}_{2}-\mathrm{CuO}$ Nanocomposite

The enhanced hydrophilic properties of the nanocomposite could increase the thin film self-cleaning ability, which based on Figure 6b, the thin film coated with the more hydrophilic nanocomposite has fewer amount of dirt, since the more hydrophlic properties of a thin film causes the higher amount of $\mathrm{H}_{2} \mathrm{O}$ or hydroxyl group that could be adsorbed, resulting in a more thicker layer of water at the surface of the thin film ${ }^{4), 23)}$ that could prevent more dirt and could be washed easily. Those were the benefits of having a self-cleaning material which reduce the consumption of detergent used to clean or wash the material.

The results in Figure 6 implies that when the $\mathrm{SiO}_{2}$ composition is higher than $33 \%$, the contact angle will decrease meaning that it has less hydrophilic properties. The increase of $\mathrm{SiO}_{2}$ content will reduce the photogenerated hole and electron so that the oxygen vacancies would be less occured, but due to the presence of Ti-O-Si bond that increase the surface acidity, the chemisorption or physisorption of $\mathrm{H}_{2} \mathrm{O}$ would still be increased even with the decrease of oxygen vacancies, so the synergis between the oxygen vacancies and surface acidity to improve the hydrophlic properties of the nanocomposite will occured until $33 \% \mathrm{SiO}_{2}$ composition and when the composition of $\mathrm{SiO}_{2}$ is higher than $33 \%$, the less oxygen vacancies would be more dominant than the increase of surface acidity that would overall lower the hydrophilic properties.

There was a significant difference in the hydrophilic characteristics between $\mathrm{CuO}-\mathrm{TiO}_{2}-33 \% \mathrm{SiO}_{2} \mathrm{M} 1$ and $\mathrm{M} 2$ nanocomposite, where the hydrophilicity of M2 nanocomposite is lower than $\mathrm{M} 1$ even though the two nanocomposites have the same composition of $\mathrm{TiO}_{2}-\mathrm{SiO}_{2}$. Thus, different morphologies can affect the hydrophilic properties of the nanocomposite, where based on the morphology illustration, it was believed that in M2 nanocomposite, most of $\mathrm{CuO}$ does not inhibits $\mathrm{TiO}_{2}$ lattice but are dispersed on $\mathrm{SiO}_{2}$ so that it does not function as an electron trapper that caused more recombination holes and electrons than M1 nanocomposite, therefore less oxygen vacancies produced in M2 nanocomposite.

\section{Conclusion}

From the experimental data, it can be concluded that $\mathrm{TiO}_{2}-\mathrm{SiO}_{2}-\mathrm{CuO} \mathrm{M} 1$ and $\mathrm{M} 2$ nanocomposite possess selfcleaning properties that could decolorize methylene blue and has hydrophilic properties, which $33 \% \mathrm{SiO}_{2}$ mole composition in $\mathrm{TiO}_{2}-\mathrm{SiO}_{2}-\mathrm{CuO}$ nanocomposite has the best self-cleaning actvities that has $80 \%$ efficiency at decolorization of methylene blue in 5 minutes and possess superhydrophilic properties. In the scope of self-cleaning activities, the $\mathrm{TiO}_{2}-\mathrm{SiO}_{2}-\mathrm{CuO} \mathrm{M} 1$ nanocomposite which most of the $\mathrm{CuO}$ were at $\mathrm{TiO}_{2}$ is superior than $\mathrm{M} 2$ nanocomposite which most of the $\mathrm{CuO}$ inhibits $\mathrm{SiO}_{2}$.

\section{Acknowledgements}

This project was supported financially by the program of PIT 9 University of Indonesia 2019 and the Contract Number: NKB-0077/UN2.R3.1/HKP.05.00/2019

\section{References}

1) A. Berendjchi, R. Khajavi and M. E. Yazdanshenas, International Journal of Green Nanotechnology. 1, 1943 (2013).

2) J. Huang, S. Li, M. Ge, L. Wang, T. Xing, G. Chen, X. Liu, S. S. Al-Deyab, K. Zhang and T. Chen, Journal of Materials Chemistry A. 3 (6), 2825 (2015).

3) S. Chen, Y. Guo, H. Zhong, S. Chen, J. Li, Z. Ge and J. Tang, Chemical Engineering Journal. 256, 238 (2014).

4) K. Guan, Surface and Coatings Technology. 191 (2-3), 155 (2005).

5) A. L. Linsebigler, G. Lu and J. T. Yates Jr, Chemical reviews. 95 (3), 735 (1995).

6) T. López, G. Jardon, E. Gomez, A. Gracia, A. Hamdan, L. Cuevas, P. Quintana and O. Novaro, J. Mater. Sci. Eng. 4 (06), 1 (2015).

7) S. Mathew, P. Ganguly, S. Rhatigan, V. Kumaravel, C. Byrne, S. Hinder, J. Bartlett, M. Nolan and S. Pillai, 
Applied Sciences. 8 (11), 2067 (2018).

8) R. Mohamed, I. Mkhalid, S. Al-Thabaiti and M. Mokhtar, Journal of nanoscience and nanotechnology. 13 (7), 4975 (2013).

9) Slamet, H. W. Nasution, E. Purnama, S. Kosela and J. Gunlazuardi, Catalysis Communications. 6 (5), 313 (2005).

10) I. Perelshtein, G. Applerot, N. Perkas, E. Wehrschuetz-Sigl, A. Hasmann, G. Gübitz and A. Gedanken, Surface and Coatings Technology. 204 (12), 54 (2009).

11) M. Riazian, Journal of Nanostructures 4 (4), 433 (2014).

12) H. Hirakawa, M. Katayama, Y. Shiraishi, H. Sakamoto, K. Wang, B. Ohtani, S. Ichikawa, S. Tanaka and T. Hirai, ACS applied materials \& interfaces. 7 (6), 3797 (2015).

13) D. Wu, M. Long, J. Zhou, W. Cai, X. Zhu, C. Chen and Y. Wu, Surface and Coatings Technology. 203 (24), 3728 (2009).

14) A. O. Ibhadon and P. Fitzpatrick, Catalysts. 3 (1), 189 (2013).

15) M. Ezaki and K. Kusakabe, Evergreen. 1 (2), 7 (2014).

16) A. Mishra and B. S. Butola, Cellulose. 24 (8), 3555 (2017).

17) I. M. Ulfah, K. Gibran, B. M. Bachtiar, M. Ibadurrohman and Slamet, Biomedical Engineering: Applications, Basis and Communications. 31 (06), 1950047 (2019).

18) X. Yang, C. Cao, L. Erickson, K. Hohn, R. Maghirang and K. Klabunde, Applied Catalysis B: Environmental. 91 (3-4), 657 (2009).

19) K. Taira and H. Einaga, Evergreen. 5 (4), 13 (2018).

20) B. Sun, A. V. Vorontsov and P. G. Smirniotis, Langmuir. 19 (8), 3151 (2003).

21) M. Janczarek, A. Zielińska-Jurek, I. Markowska and J. Hupka, Photochemical \& Photobiological Sciences. 14 (3), 591 (2015).

22) T. Yuranova, R. Mosteo, J. Bandara, D. Laub and J. Kiwi, Journal of Molecular Catalysis A: Chemical. 244 (1-2), 160 (2006).

23) X. Feng, S. Zhang and X. Lou, Colloids and Surfaces B: Biointerfaces. 107, 220 (2013).

24) H. A. Budiarti, R. N. Puspitasari, A. M. Hatta and D. D. Risanti, Procedia engineering. 170, 65 (2017).

25) K. Dhanalekshmi and K. Meena, Spectrochimica Acta Part A: Molecular and Biomolecular Spectroscopy. 128, 887 (2014).

26) J. Zhong, J. Zeng, J. Li, S. Huang, W. Jiang, Z. Tang and M. Li, Journal of Advanced Oxidation Technologies. 17 (1), 99 (2014). 